\title{
Ectopic thymus of the neck-report of three examples in children
}

\author{
C. T. LEWIS \\ F.R.C.S.
}

\author{
Queen Elizabeth Hospital for Children, Hackney Road, London
}

\begin{abstract}
Summary
Three children with ectopic thymic tumours of the neck are described. One solid mass was situated in the midline whilst two were unilateral and cystic. The difficulties of diagnosis and surgical removal are stressed and the question of interference to immunological competence discussed.

Small lobules of aberrant thymus are not infrequently found in the neck, often within the thyroid gland, possibly present in up to $20 \%$ of humans (Goldstein and Mackay, 1969; Gilmour, 1941). However, ectopic thymic tissue of size sufficient to produce a palpable swelling of the neck is uncommon. In a review of the forty-six such cases recorded in the English literature, Hinds et al. (1970) found that the majority were diagnosed in childhood.
\end{abstract}

\section{Case 1}

A 7-year-old girl was noticed to have a tumour of the neck from the age of 6 months. It increased in size gradually but produced no symptoms. On examination, there was a midline, apparently fluctuant lump which moved on swallowing but had no superficial fixation. The pre-operative diagnosis lay between a midline epidermoid cyst and a thyroglossal cyst.

At operation a solid mass with no obvious vascular supply lay deep to the infrahyoid muscles and extended inferiorly behind the sternum, its superior pole being the palpable midline swelling (Fig. 1). It proved to be a discrete lobulated structure about $5 \mathrm{~cm}$ long and $1.5 \mathrm{~cm}$ wide which was shown microscopically to be composed of normal thymic tissue.

A lateral tomogram 4 weeks after surgery demonstrated an apparently normal retrosternal thymus.

\section{Case 2}

An 8-year-old boy presented with a swelling of the left side of the neck which had been present for one month. On examination, this clinically euthyroid child had a firm ovoid mass which moved on swallowing and appeared to be an integral part of, if not the entire, left lobe of thyroid. Thyroiditis and carcinoma of the thyroid were considered as possible diagnoses.

Present address: Department of Cardio-Vascular and Thoracic Surgery, The London Hospital, London E1 1BB.

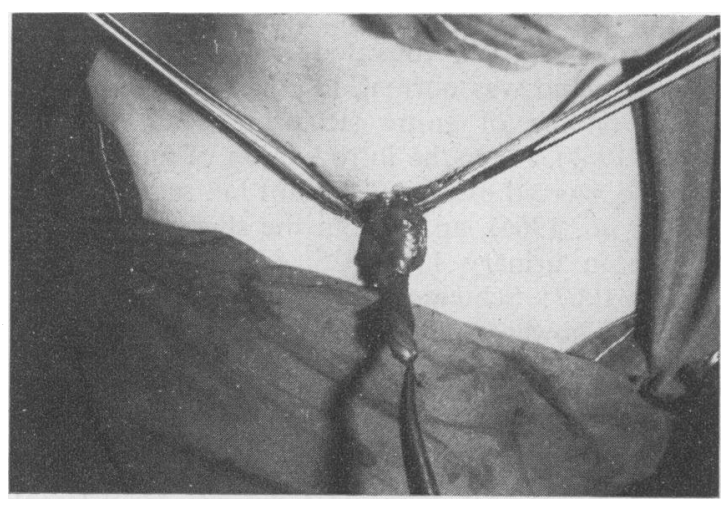

FIG. 1. Case 1. Discrete mid-line thymic tumour being delivered through an incision about $50 \mathrm{~mm}$ above the sternal notch.

At operation, a thin-walled cyst, quite separate from the thyroid, was adherent to the infrahyoid muscle and the carotid sheath from which it was removed completely with considerable difficulty. It weighed $29 \mathrm{~g}$, measured $5.8 \times 2.8 \mathrm{~cm}$ and contained yellow fluid with visible cholesterol crystals. Its wall was $0.3-0.5 \mathrm{~cm}$ thick and included several smaller cysts. Microscopically each cyst was lined with a single layer of flat endothelium: the wall was fibrous and included areas of involuted thymus and collections of cholesterol crystals some of which were associated with a foreign body giant cell reaction.

\section{Case 3}

A 12-year-old boy presented with a 3-month history of a swelling in the right side of his neck which initially had been painful and recently had increased in size.

On examination an indiscrete cystic mass measuring about $3 \times 2 \mathrm{~cm}$ was palpable anterior to the sternomastoid muscle. It was diagnosed with confidence as a branchial cyst.

At operation it extended from the angle of the mandible, deep to the sternomastoid muscle and close to the internal jugular vein whilst the vagus nerve coursed through it. It consisted of a number of cysts containing gelatinous yellow fluid and cholesterol crystals. The cysts were lined with cells 


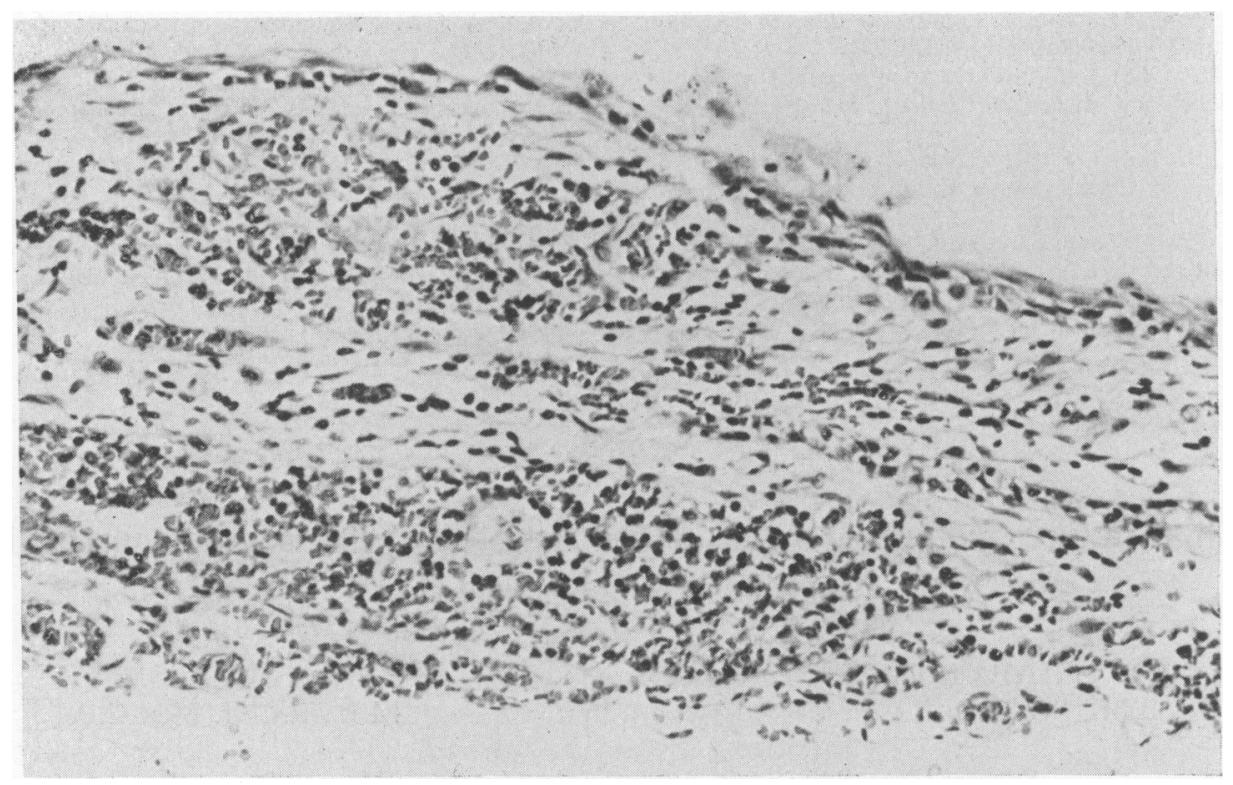

Fig. 2. Case 3. Wall of cyst showing cellular lining and surrounding thymic tissue.

resembling those found normally in Hassell's corpuscles and the solid elements of the mass consisted of degenerate thymic tissue (Fig. 2). A normal parathyroid gland was included.

\section{Discussion}

The thymus gland is derived from the third and fourth pharyngeal pouches as paired structures in the fourth week of intra-uterine life which migrate caudally to a position between a sternum and heart and separate from the pharynx whilst the cephalic rudiments disappear (Warkany, 1971; Arey, 1965). Speer (1938) suggested that retention of thymic tissue in the neck could be explained in various ways. These included: a proliferation of isolated remnants of branchial cleft, thymo-pharyngeal ducts or thymic tubules; (b) failure of the cephalic processes of the elongating thymus to involute; (c) neoplastic proliferation of cephalic remnants (Wadas, 1934); (d) overgrowth of the connective tissue stroma involved in the development of the thymus. Hinds et al. (1970) stated that $95 \%$ of thymic tumours in the neck were unilateral and that $90 \%$ were cystic. The difficulty of pre-operative diagnosis is illustrated by the variety of suggested diagnoses in the three patients presented. These examples, particularly cases 2 and 3, show that the mass may extend widely and deeply in the tissues of the neck and may involve important structures, rendering surgical removal considerably more difficult than is generally reported in the literature.
Interference with the immunological status quo is obviously an important consideration when thymus tissue is removed from a child. In fact, only one case had lateral tomography specifically undertaken and this suggested the remaining presence of normal thymus, as would probably be the usual case. Even if, however, the removed portion was the entire functioning thymus, it is unlikely that this would interfere with immunological competence as man appears to be immunologically more mature at birth than the experimental animals normally used for investigation (Goldstein and Mackay, 1969) and, indeed, total thymectomy has been undertaken in neonates and young children without apparent interference with the mechanism (Gotoff, 1968; Zollinger et al., 1964) although the theoretical risk remains of subsequent predisposition to neoplasia in the long term (Waksman, 1964; Goldstein and Mackay, 1969).

\section{Acknowledgments}

I wish to thank Mr V. A. J. Swain for permission to publish the clinical details and Dr N. E. France for the pathological findings.

\section{References}

Arey, L.B. (1965) Developmental Anatomy, 7th edition, p. 10. W. B. Saunders: Philadelphia.

GILMOUR, J.R. (1941) Some developmental abnormalities of the thymus and parathyroids. Journal of Pathology and Bacteriology, 52, 213. 
Goldstein, G. \& MACKAy, I. (1969) The Human Thymus. Heinemann, Medical Books Ltd: London.

GotofF, S.P. (1968) Lymphocytes in congenital immunological deficiency diseases. Clinical and Experimental Immunology, 3, 845.

Hinds, E.A., Linkner, L.M., Cloud, D.T. \& Trump, D.S. (1970) Ectopic thymic tissue of the neck. Journal of Paediatric Surgery, 5, 460.

SPEER, F.D. (1938) Thymic cysts: A report of thymus presenting cysts of three types. New York Medical College. Flower Hospital Bulletin, 1, 142.
WADAS, A. (1934) Thymoma intratracheals. Zentralblatt für allgemeine Pathologie und pathologische Anatomie, 60, 308.

WaKsman, B.H. (1964) Thymus experimentation. New England Journal of Medicine, 270, 1018

WARKANY, J. (1971) Congenital Malformations. 1971 Year Book, Medical Publishers Inc.

Zollinger, R.M. JR, LindeM, M.C., Filler, R.M., Corson, J.M. \& WiLSON, R.E. (1964) Effect of thymectomy on skin homograft survival in children. New England Journal of Medicine, 270, 707.

\section{Renal failure and suprarenal calcification after secondary haemorrhagic disease in a newborn baby}

\author{
M. W. MONCRIEFF \\ B.M., B.Ch., M.R.C.P.
}

\author{
H. HARgReaves \\ M.B., B.Chir. M.R.C.P.
}

\section{Special Care Baby Unit, Nightingale Maternity House, Derby}

\begin{abstract}
Summary
A newborn baby who was severely asphyxiated at birth developed secondary haemorrhagic disease which was treated successfully with intravenous heparin. However, she was later found to have supra-renal calcification, chronic renal insufficiency and hypertension. It is felt that prompt treatment of conditions that predispose to secondary haemorrhagic disease is very important as, once this has occurred, treatment may not prevent permanent damage to vital organs.
\end{abstract}

\section{Introduction}

Secondary haemorrhagic disease of the newborn occurs mainly in association with severe birth asphyxia, hypothermia and rhesus haemolytic disease (Chessells and Wigglesworth, 1970) and often results from disseminated intravascular coagulation (Boyd, 1967). Treatment with heparin (Whaun, Ormson and Oski, 1971) or exchange transfusion (Gross and Melhorn, 1971) has been advocated, but the mortality is $60 \%$ (Whaun et al., 1971). Although fibrin deposits have been found in many organs at autopsy (Boyd, 1967) we have not found reports of permanent damage to organs other than the brain in the survivors (Bryant et al., 1970).

\section{Case report}

This baby girl was born at 42 weeks' gestation after an antepartum haemorrhage by normal vertex delivery in a nearby maternity home and weighed $3.85 \mathrm{~kg}$. She failed to breathe and after $10 \mathrm{~min}$ was treated with positive pressure ventilation via an endotracheal tube, regular respiration being estab- lished at $\mathbf{4 0} \mathrm{min}$. She was then transferred to the Special Care Baby unit. On arrival she was moribund, with no spontaneous movements, apart from shallow respiration, no primitive reflexes and heart rate of $90 / \mathrm{min}$. Sodium bicarbonate was given intravenously and she was nursed in $59 \%$ oxygen. Her heart rate rose to $140 / \mathrm{min}$, respiration improved and some spontaneous movements occurred. Investigations gave the following results: $\mathrm{Hb} 11.7 \mathrm{~g} / 100 \mathrm{ml}$, platelets $103,000 / \mathrm{mm}^{3}$, prothrombin activity $12 \%$, pH 7.29, $\mathrm{PCO}_{2} 38 \mathrm{mmHg}, \mathrm{Po}_{2} 180 \mathrm{mmHg}$, and serum bicarbonate $18 \mathrm{mEq} / 1$. She was given $80 \mathrm{ml}$ of blood and $1 \mathrm{mg}$ of vitamin $\mathrm{K}_{1}$.

The following day her haemoglobin had fallen to $10.6 \mathrm{~g} / 100 \mathrm{ml}$ and she was given a further blood transfusion. Over the next 4 days she had a number of fits which were treated with phenobarbitone. Her general condition improved with increase in activity and the Moro reflex returned, although she could not suck and had marked head retraction and severe hypotonia. Her urine contained a large amount of blood, but was not infected and the kidneys were not enlarged. On the sixth day of life her haemoglobin had fallen to $8.4 \mathrm{~g} / 100 \mathrm{ml}$, platelets to $12,000 / \mathrm{mm}^{3}$, and she bled profusely from a heel prick. A further blood transfusion was given and later that day exchange transfusion with fresh, heparinized blood was carried out. After this her haemoglobin concentration rose to $13.8 \mathrm{~g} / 100 \mathrm{ml}$ and platelets to $115,000 / \mathrm{mm}^{3}$.

However, the next day the haemoglobin and platelet count fell again and fibrin degradation products were detected in the serum. After another 